\title{
Study on the Harmful Substances and Food Safety in the Ruditapes philippinarum at the Xiangshan Bay
}

\author{
Genhai Zhu \\ Key laboratory of marine ecosystem and \\ biogeochemistry, State Oceanic Administration \\ Second Institute of Oceanography, SOA \\ Hangzhou 310012, China \\ azhugenhai@21cn.com
}

\author{
Mao Jin, Weihua Song, Qingsong Zhou, Weihua \\ Feng and Chunfang $\mathrm{Wu}$ \\ Key Laboratory of Engineering Oceanography \\ Second Institute of Oceanography, SOA \\ Hangzhou 310012, China
}

\author{
Jingjing Liu \\ Key laboratory of marine ecosystem and \\ biogeochemistry, State Oceanic Administration \\ Second Institute of Oceanography, SOA \\ Hangzhou 310012, China
}

\begin{abstract}
During the period from January 2011 to May 2015, we analyzed and studied the contents of harmful substances ( $\mathrm{Hg}, \mathrm{Pb}, \mathrm{As}, \mathrm{Cd}, \mathrm{Cu}, \mathrm{Zn}, \mathrm{Cr}$, Petroleum hydrocarbons, Polychlorinated biphenyls, Fecal coliforms) which were collected from the body of 300 Ruditapes philippinarum at the Xiangshan Bay areas and food safety. The results indicate that the average contents of the harmful substances $\mathrm{Hg}, \mathrm{Pb}$, As, Cd, $\mathrm{Cu}, \mathrm{Zn}$, total $\mathrm{Cr}$, Petroleum hydrocarbons, polychlorinated biphenyls in the body of Ruditapes philippinarum were respectively $0.016,0.122,0.68$, 0.052, $0.82,12.06,0.22,4.6,0.002 \mathrm{mg} / \mathrm{kg}$ (wet) and Fecal coliforms 220MPN/100g. The harmful substances in the Ruditapes philippinarum is closely related to the quality of the sea water and the bottom environmental conditions, and the contents of harmful substances and sediments at the bottom and the heavy metal contents in the sea water are positive relationship; The average content for the adult body length $28-38 \mathrm{~mm}$ of Ruditapes philippinarum is high, and the average content of larval body length $5-15 \mathrm{~mm}$ is low. So the harmful substances and the body length are positive relationship. We evaluated that the contents of harmful substances in the Ruditapes philippinarum don't exceed the standard and can be used for the group to eat safely as the international standards and "The Concentration Limits for the Toxic and Harmful substances in pollution-free food and aquatic products".
\end{abstract}

Keywords- Xiangshan Bay; Ruditapes philippinarum; Harmful substances; Food safety.

\section{PREFACE}

The Xiangshan Bay locates in the northeastern coast of Zhejiang, which is in the east of Zhoushan islands, and its north is close to Hangzhou Bay, its south is connected to Sanmen Bay. It is a long and narrow semi-closed gulf which penetrates into inland from northeast and southwest direction. The total area is about $563 \mathrm{~km}^{2}$, which water area is around $70 \%$, the mudflat area is around $30 \%$, intertidal zone and fertile sediments at the bottom of sea water are growth and reproduction areas provided for Ruditapes philippinarum etc. marine shellfish. The Xiangshan Bay is the important base for marine fishery of our country, and is one of the most important aquaculture Base in Zhejiang province, the East China Sea.

In recent years, with the rapid economic development in the coastal areas, a large number of industrial wastewater and urban sewage were discharged into the sea, which cause many cultivation areas polluted heavily gradually by the toxic and biorefractory pollutants, the quality of sea water was deteriorated, which affects the aquaculture and ecological environments to some extent. The pollutant contents in aquatics reflect the source of contaminants, the degree of pollution and the bioavailability, which is one of the important indicators. The shellfish distributes widely in the sea water. They have high adaptability, and they have strong capacity to gather variety of pollutants, so it is the important biological indicator species of marine pollution. The growing position of molluscan shellfish is comparatively stable, so they are easily to be polluted. The Ruditapes philippinarum belong to filter feeding aquatics. When they filter feeding bait organisms, they also inhale the harmful substances into their body, which cause the harmful substances gathered in their body. If people eat the polluted shellfish by harmful substances, they will easily get disease and health will be threatened, even more, the local food poisoning events will be followed. About the study of contents distribution (which includes $\mathrm{Hg}, \mathrm{Pb}, \mathrm{As}$, $\mathrm{Cd}, \mathrm{Cu}, \mathrm{Zn}, \mathrm{Cr}$, Petroleum hydrocarbons, polychlorinated biphenyls, Fecal coliforms) in the body of Ruditapes philippinarum, there are many reports about the analysis of the heavy metals in the body of shellfish or individual 
factors at home and abroad, but until now reports have not been found about the analysis and study of the harmful substances in the different body length of Ruditapes philippinarum $^{[1-9]}$.

The author analyzed and studied about the contents of harmful substances (which includes $\mathrm{Hg}, \mathrm{Pb}, \mathrm{As}, \mathrm{Cd}, \mathrm{Cu}$, $\mathrm{Zn}$, Cr, Petroleum hydrocarbons, polychlorinated biphenyls, Fecal coliforms) of the different body length of Ruditapes philippinarum from the low tide of intertidal zone at the Xiangshan Bay to $10 \mathrm{~m}$ depth sea water, which provide the scientific basis for the environment quality assessment of producing areas of Ruditapes philippinarum at the Xiangshan Bay and human health \& safety and environmental protection of marine ecological resources.

\section{MATERIALS AND METHODS}

\section{A. Sampling}

The Ruditapes philippinarum (Adams \& Reeve, 1850) [=Venerupis philippinarum (A. Adams \& Reeve, 1850) ] samples were obtained in middle or low tide area to $10 \mathrm{~m}$ deep sea area sediment in Xiangshan Bay during the period from January 2011 to May 2015, which went through five years' spring, summer, autumn, and winter. See research station in Figure 1. The samples were collected from the low tide area of intertidal zone. The sediments samples of sea were collected by dredge $(0.1$ $\mathrm{m}^{2}$ ) and trawl net. The body length of Ruditapes philippinarum is $15-35 \mathrm{~mm}$, and the height is $10-25 \mathrm{~mm}$, but we collected the $5-15 \mathrm{~mm}$ larvae to compare too. After processed, these samples were removed mantle, stomach contents, muscles, cavity fluid ${ }^{[10-12]}$

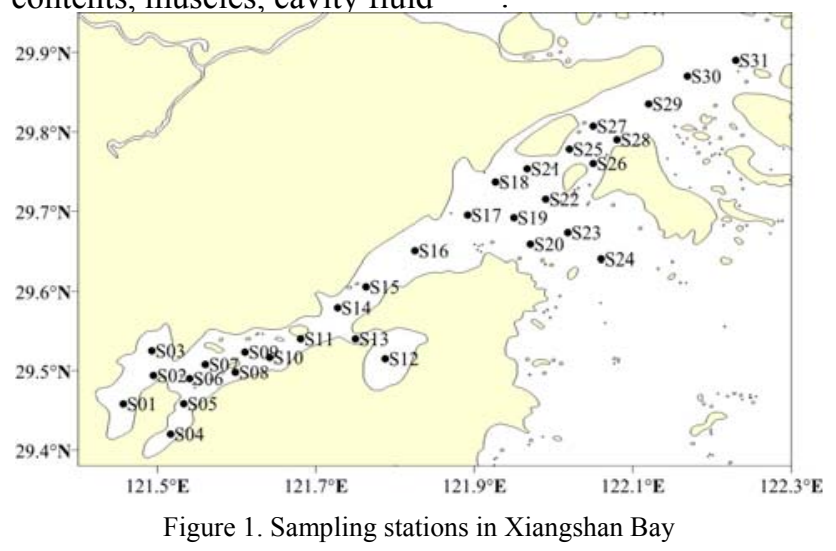

\section{B. Methods}

According to the requirements for samples collection in "The Specification for Marine Monitoring", we collected $1.0 \mathrm{~kg}$ similar individual body sizes, and washed clearly in sea water at that time, then put them into double polyethylene bags to store with freezing, and took them back the laboratory to be processed. We put freezing samples in the refrigerator for overnight, some of samples were thawed and removed the soft tissue with tweezers and clean plastic knife after washed with distilled water. Then we homogenized at least 10 or more individual soft tissue in homogenizer and freeze-dried to be tested after the water dry. We used cold atomic fluorescence mercury measurement instrument to test the content of Hydrargyrum, and used atomic fluorescence spectrophotometry instrument to test the content of
Arsenic element, we used graphite furnace atomic absorption spectrophotometry to test the contents of $\mathrm{Cu}$, Plumbum, $\mathrm{Cd}$ and $\mathrm{Cr}$ elements, and used flame atomic absorption spectrophotometry to test the content of $\mathrm{Zn}$. The harmful substances of organism include $\mathrm{Hg}, \mathrm{Pb}, \mathrm{As}$, $\mathrm{Cd}, \mathrm{Cu}, \mathrm{Zn}, \mathrm{Cr}$, Petroleum hydrocarbons, polychlorinated biphenyls, Fecal coliforms and other monitoring parameters. $\mathrm{Cu}, \mathrm{Cd}$, Plumbum, Total Chromium were used by flameless atomic absorption spectrophotometry; $\mathrm{Zn}$ was used flame atomic absorption spectrophotometry measurement; Hydrargyrum and Arsenic were used atomic absorption spectrophotometry measurement. Coliforms: "Coliform Bacteria Determination" (GB4789.3-2003).

All samples were collected, stored, transported, pretreated, analyzed and tested according to the requirements of "Specification of Marine Monitoring”(GB/T12763-2007) and "Specification of Marine Monitoring"(GB173782007) ${ }^{[13-16]}$.

\section{RESULTS}

\section{A. Hydrargyrum $(\mathrm{Hg})$ in the Ruditapes philippinarum}

The detection value of Hydrargyrum $(\mathrm{Hg})$ contents in the Ruditapes philippinarum at the Xiangshan Bay is $0.006 \sim 0.018 \mathrm{mg} / \mathrm{kg}$, the average value is $0.016 \mathrm{mg} / \mathrm{kg}$, the contents of Hydrargyrum accords with the quality requirements of pollution-free aquatic products which indicators $\leq 0.3 \mathrm{mg} / \mathrm{kg}$ (Table I.).

\section{B. Plumbum $(\mathrm{Pb})$ in the Ruditapes philippinarum}

The detection value of Plumbum $(\mathrm{Pb})$ contents in the Ruditapes philippinarum at the Xiangshan Bay is $0.008 \sim 0.223 \mathrm{mg} / \mathrm{kg}$, the average value is $0.122 \mathrm{mg} / \mathrm{kg}$, The contents of Plumbum accords with the quality requirements of pollution-free aquatic products which indicators $\leq 0.5 \mathrm{mg} / \mathrm{kg}$ (Table I.).

\section{Arsenic (As) in the Ruditapes philippinarum}

The detection value of Arsenic (As) contents in the Ruditapes philippinarum at the Xiangshan Bay is $0.24 \sim 0.77 \mathrm{mg} / \mathrm{kg}$, the average value is $0.68 \mathrm{mg} / \mathrm{kg}$, The contents of Arsenic accords with the quality requirements of pollution-free aquatic products which indicators $\leq 1.0$ $\mathrm{mg} / \mathrm{kg}$ (Table I.).

\section{Cadmium (Cd) in the Ruditapes philippinarum}

The detection value of Cadmium (Cd) contents in the Ruditapes philippinarum at the Xiangshan Bay is $0.03 \sim 0.06 \mathrm{mg} / \mathrm{kg}$, the average value is $0.052 \mathrm{mg} / \mathrm{kg}$, The contents of Cadmium accords with the quality requirements of pollution-free aquatic products which indicators $\leq 0.1 \mathrm{mg} / \mathrm{kg}$ (Table I.).

\section{E. Copper $(\mathrm{Cu})$ in the Ruditapes philippinarum}

The detection value of Copper $(\mathrm{Cu})$ contents in the Ruditapes philippinarum at the Xiangshan Bay is $0.08 \sim 1.26 \mathrm{mg} / \mathrm{kg}$, the average value is $0.82 \mathrm{mg} / \mathrm{kg}$, the contents of Copper accords with the quality requirements of pollution-free food and aquatic products which indicators $\leq 50.0 \mathrm{mg} / \mathrm{kg}$ (Table I.).

\section{F. Zinc ( $\mathrm{Zn})$ in the Ruditapes philippinarum}

The detection value of $\mathrm{Zn}$ contents in the Ruditapes philippinarum at the Xiangshan Bay is $5.0 \sim 14.2 \mathrm{mg} / \mathrm{kg}$, 
the average value is $12.06 \mathrm{mg} / \mathrm{kg}$, the contents of Zinc accords with the quality requirements of pollution-free food and aquatic products which indicators $\leq 250.0$ $\mathrm{mg} / \mathrm{kg}$ (Table I.).

\section{G. Total Chromium (Cr) in the Ruditapes philippinarum}

The detection value of $\mathrm{Cr}$ contents in the Ruditapes philippinarum at the Xiangshan Bay is $0.06 \sim 0.36 \mathrm{mg} / \mathrm{kg}$, the average value is $0.22 \mathrm{mg} / \mathrm{kg}$, the contents of total Chromium accords with the quality requirements of pollution-free food and aquatic products which indicators $\leq 2.0 \mathrm{mg} / \mathrm{kg}$ (Table I.).

$H$. Petroleum hydrocarbons (Phs) and polychlorinated biphenyls (PCBs) in the Ruditapes philippinarum

The detection value of Petroleum hydrocarbons contents in the Ruditapes philippinarum is $1.7 \sim 6.1 \mathrm{mg} / \mathrm{kg}$, the average value is $4.6 \mathrm{mg} / \mathrm{kg}$, we take the standard value of Petroleum hydrocarbons $(\leq 15 \mathrm{mg} / \mathrm{kg})$ as the evaluation criterion according to "The Toxic and Harmful Substances Limits of NY/T 5073-2006 pollution-free food and aquatic products", the contents of Petroleum hydrocarbons accords with the quality requirements of pollution-free food and aquatic products which indicators $\leq 15.0 \mathrm{mg} / \mathrm{kg}$ (Table I.).

The detection value of polychlorinated biphenyls contents in the Ruditapes philippinarum at the Xiangshan Bay is $0.000 \sim 0.003 \mathrm{mg} / \mathrm{kg}$, the average value is 0.002 $\mathrm{mg} / \mathrm{kg}$, We take the standard value of polychlorinated biphenyls as evaluation criterion, the contents of polychlorinated biphenyls accords with the quality requirements of pollution-free food and aquatic products which indicators $\leq 0.2 \mathrm{mg} / \mathrm{kg}$ (Table I.).

I. Fecal coliforms in the Ruditapes philippinarum at the sea water of Xiangshan Bay

The detection value of Fecal coliforms contents in the Ruditapes philippinarum at the Xiangshan Bay is $18 \sim 280 \mathrm{MPN} / 100 \mathrm{~g}$, the average value is $220 \mathrm{MPN} / 100 \mathrm{~g}$, we take the standard value of Fecal coliforms $(<300$ MPN100g) as evaluation criterion, the contents of Fecal coliforms accords with the quality requirements of pollution-free food and aquatic products which indicators $<300$ MPN/100g(Table I.).

TABLE I. THE CONTENTS OF THE HARMFUL SUBSTANCES IN THE RUDITAPES PHILIPPINARUM AT THE XIANGSHAN $\mathrm{BAY}(\mathrm{MG} / \mathrm{KG}, \mathrm{WET})$

\begin{tabular}{cccc}
\hline Item & Range & Average & QS $^{*}$ \\
\hline $\mathrm{Hg}$ & $0.006-0.018$ & 0.016 & $\leq 0.3$ \\
$\mathrm{~Pb}$ & $0.008-0.223$ & 0.122 & $\leq 0.5$ \\
$\mathrm{As}$ & $0.24-0.77$ & 0.68 & $\leq 1.0$ \\
$\mathrm{Cd}$ & $0.03-0.06$ & 0.052 & $\leq 0.1$ \\
$\mathrm{Cu}$ & $0.08-1.26$ & 0.82 & $\leq 50.0$ \\
$\mathrm{Zn}$ & $5.0-14.2$ & 12.06 & $\leq 20.0$ \\
$\mathrm{Cr}$ & $0.06-0.36$ & 0.22 & $\leq 2.0$ \\
Petroleum hydrocarbons & $1.7-6.1$ & 4.6 & $\leq 15.0$ \\
polychlorinated biphenyls & $0.000-0.003$ & 0.002 & $\leq 0.2$ \\
$\begin{array}{c}\text { Fecal coliforms } \\
\text { /MPN·(100g) }\end{array}$ & $18-280$ & 120 & $<300$ \\
\hline * QS (Aquatic Quality Standards). The Concentration Limits for the Toxic
\end{tabular}

and Harmful substances in pollution-free food and aquatic products.

\section{DISCUSSION}

a) The harmful substances in the Ruditapes philippinarum is closely related to the quality of the sea water and the bottom environmental conditions, and the contents of harmful substances and sediments at the bottom and the heavy metal contents in the sea water are positive relationship; The average content for the adult body length $28-38 \mathrm{~mm}$ of Ruditapes philippinarum is high, and the average content of larval body length $5-15 \mathrm{~mm}$ is low. So the harmful substances and the body length are positive relationship (Figure 2., Figure 3., Figure 4., Figure 5.)

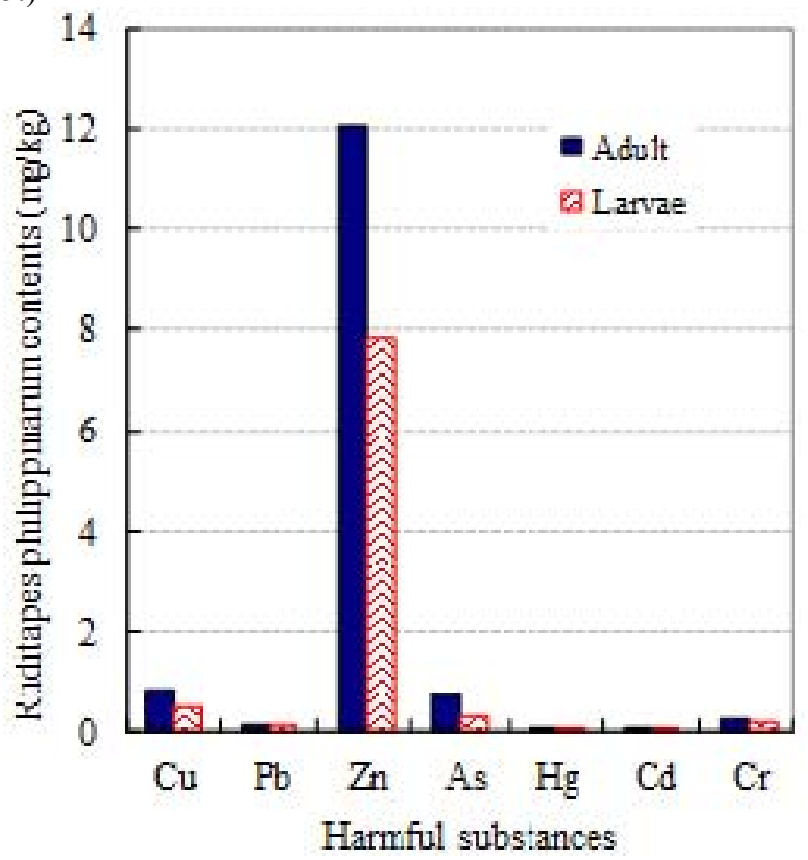

Figure 2. The comparison about the contents of harmful substances in the body of adults and larvae of Ruditapes philippinarum at the Xiangshan Bay

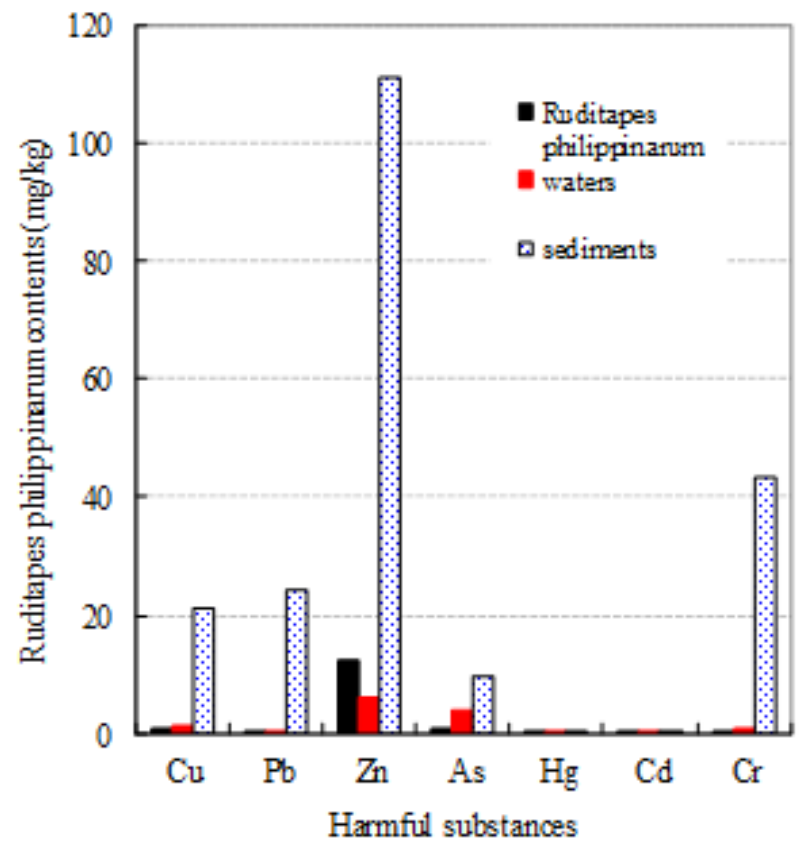

Figure 3. The comparison about the contents of harmful substances in the Ruditapes philippinarum, sea water and the contents of sediments at the Xiangshan Bay 

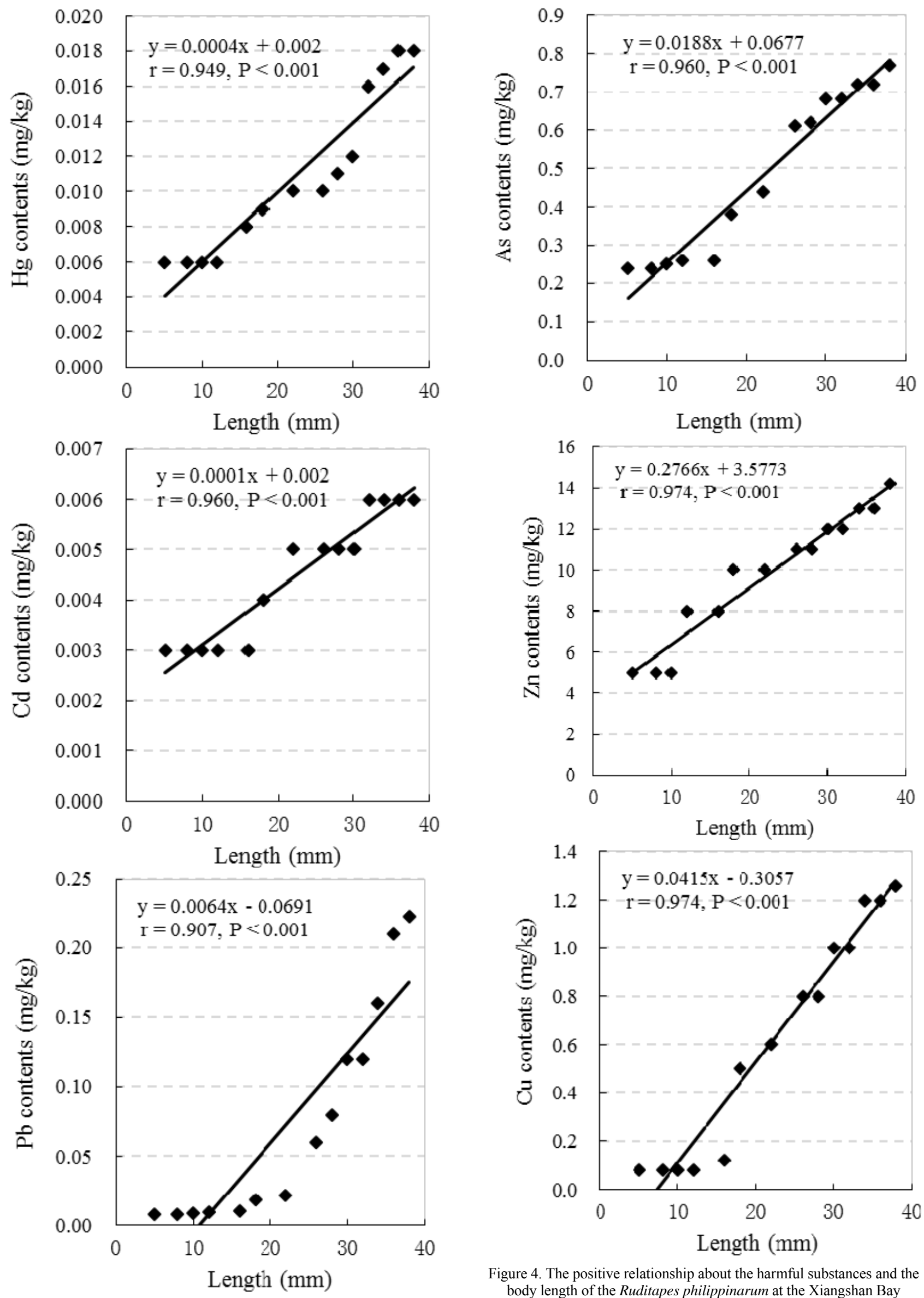

Figure 4. The positive relationship about the harmful substances and the body length of the Ruditapes philippinarum at the Xiangshan Bay 

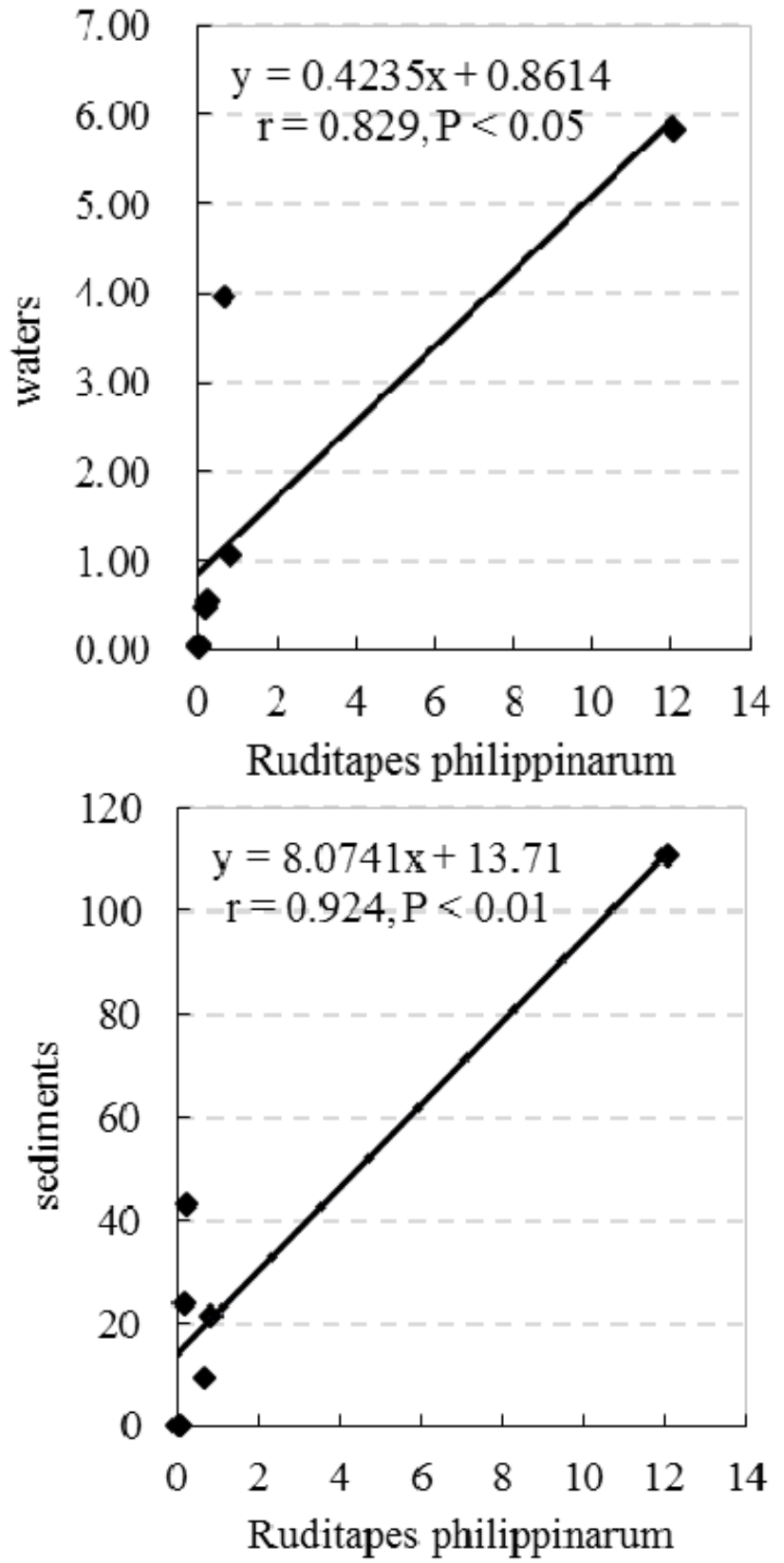

Figure 5. The correlation about the harmful substances in the Ruditapes philippinarum and the sea water and the sediments at the Xiangshan Bay

b) Marine life particularly for economic shellfish is a very important food sources for coastal groups. Marine life tastes good and delicious. From the view of nutritional point, they contain variety of essential protein, trace elements, amino acid and unsaturated fatty acids and so on for human body, which are the first choice, high quality foods for human. However, the pollution of marine environment causes some certain harm for groups of consumption, since aquatic foods originally should have good quality. Because marine life has their own unique biological characteristics, they have some ability to gather the heavy metals, petroleum hydrocarbons and PCBs etc. for some degree in the marine environments. As we all know, economic shellfish has the highest ability to gather the pollutants. If people eat the polluted shellfish, the marine contaminants will come into the body of people through food chain, thus damage will be caused for human body. The heavy metal elements mainly are $\mathrm{Hg}, \mathrm{Cd}, \mathrm{Pb}$, As, $\mathrm{Zn}, \mathrm{Cu}$ and total $\mathrm{Cr}$ etc. in the polluted shellfish, which all will cause damage for human body. The study for over many years indicates that the pollutants' damage for human health such as the heavy metals is from many sides and many levels. The heavy metals' pollutants have become major environment problems to threaten the development of human. Though there is no strict order of metal toxicity, $\mathrm{Hg}$ is considered the most toxic metal, then followed by $\mathrm{Cd}, \mathrm{Pb}$ and other metals, that is $\mathrm{Hg}>\mathrm{Cd}>\mathrm{Pb}>$ other metal elements ${ }^{[2,17]} . \mathrm{Hg}$ is a highly toxic substance with strong volatility. The shellfish has considerable ability to gather Hydrargyrum, $\mathrm{Hg}$ in the body of shellfish will be increased by the $\mathrm{Hg}$ contents of sea water. But the $\mathrm{Hg}$ content is very few in the Ruditapes philippinarum at the Xiangshan Bay, so it is safety to eat Ruditapes philippinarum at the Xiangshan Bay. The toxic of Plumbum for marine life is for the blood firstly, which makes the blood cells change, then cause chronic poisoning to make the muscle atrophy and damage the central nervous system, $\mathrm{Pb}$ can cause poisoning for embryo which pay more attention than it causes teratogenic embryo, and it can damage the liver etc. In general $\mathrm{Pb}$ has low solubility, which more attached to the suspended substances, and come into the ocean by rivers. They deposit large number in the estuary and harbor, Usually more than $70-90 \% \mathrm{~Pb}$ in the sea area is residual form which left in the sediments of sea bottom ${ }^{[2]}$. The $\mathrm{Pb}$ content is very few in the Ruditapes philippinarum at the Xiangshan Bay, so it is safety to eat Ruditapes philippinarum at the Xiangshan Bay. $\mathrm{Cd}$ is a highly toxic trace element, it was stipulated by the World Health Organization that human body cannot be ingested, the maximum permit to eat per people per week is only $0.3 \sim 0.44 \mathrm{mg}$. In general $\mathrm{Cd}$ in the environment flows into the sea through atmospheric deposition and wastewater discharge, some dissolve in the sea water, the other part was deposited as suspended state at the bottom of sea. Both $\mathrm{Cd}$ can be gathered easily by shellfish, and the concentration factor is high, so the damage is serious. For total Arsenic of 23 pieces shellfish samples at Nantong coastal shallows, we analyzed and studied inorganic Arsenic and other several heavy metals, and found that the average content of total Arsenic is $1.36 \mathrm{mg} / \mathrm{kg}$, the average content of inorganic Arsenic is $0.28 \mathrm{mg} / \mathrm{kg}$, the contents of inorganic Arsenic all accord with our "Safety qualification for agricultural product-Safety requirements for nonenvironmental pollution aquatic products" ${ }^{9[6]}$.The residual levels of heavy metals in the economic shellfish for the coastal of the Bohai Sea and the Yellow Sea, the result is that inorganic Arsenic did not exceed the bivalve mollusc "Safety qualification for agricultural product-Safety requirements for non-environmental pollution aquatic products" ${ }^{[4]}$. The $\mathrm{Cd}$ concentrations, which were the highest in the three hazardous metals $(\mathrm{Cd}, \mathrm{Hg}$, and $\mathrm{Pb}$ ), were significantly higher $(\mathrm{P}<0.05)$ in the bivalves and crabs than in the gastropods and cephalopods ${ }^{[18]}$.

c) Marine oil pollution is one of the most serious problems in the coastal pollution in China, but also it is one of the bigger organic pollutants for cultivation of shellfish. The aromatic ingredients and phenol ingredients in Petroleum hydrocarbons ingredients can make the cultured aquatic living beings with the smell even if the 
consistence is very low, the polycyclic aromatic compounds are 4-benzopyrene which is human carcinogen, it can gather in the fat of marine life, and pass through the food chain in the human body, which directly endanger the people's health. When people eat the polluted shellfish, which will produce the carcinogen from the Petroleum hydrocarbons especially for polycyclic aromatic hydrocarbon(PAHs), the carcinogen can be passed through the food chain and endanger human health and safety. When the consistence of Petroleum hydrocarbons in the sea water is $<0.05 \mathrm{mg} / \mathrm{L}$, the balance consistence of Petroleum hydrocarbons gathered in the shellfish is less than $25 \mathrm{mg} / \mathrm{kg}$, and is in a class $(15 \mathrm{mg} / \mathrm{kg})$ and class II $(50 \mathrm{mg} / \mathrm{kg})$ quality standard of marine shellfish in our country, and consider when the Petroleum hydrocarbons' contents in the shellfish is $\leq 25.0 \mathrm{mg} / \mathrm{kg}$, they will not affect the food safety ${ }^{[7]}$. Comparisons of the main harmful substances contents in Ruditapes philippinarum between different areas of the Xiangshan Bay and other waters (mg/kg,wet) (Table II.).

TABLE II. COMPARISONS OF THE MAIN HARMFUL SUBSTANCES CONTENTS IN RUDITAPES PHILIPPINARUM BETWEEN DIFFERENT AREAS OF THE XIANGSHAN BAY AND OTHER WATERS (MG/KG,WET)

\begin{tabular}{cccccccc}
\hline Item & Hg & Pb & As & Cd & Cu & Phs & PCBs \\
\hline $\begin{array}{c}\text { A Class } \\
\text { Standard }\end{array}$ & $\leq 0.3$ & $\leq 0.5$ & $\leq 1.0$ & $\leq 0.1$ & $\leq 50.0$ & $\leq 15.0$ & $\leq 0.2$ \\
$\begin{array}{c}\text { Xiangshan } \\
\text { Bay }\end{array}$ & 0.016 & 0.122 & 0.68 & 0.052 & 0.82 & 4.6 & $\mathbf{0 . 0 0 2}$ \\
Fuqing[9] & 0.014 & 0.20 & 0.699 & 0.170 & - & 14.3 & 0.0069 \\
Pingtan[9] & 0.018 & 0.45 & 0.256 & 0.096 & - & 8.9 & 0.0020 \\
Lianjiang[9] & 0.009 & 0.17 & 0.661 & - & - & 3.5 & 0.0069 \\
Jiaozhou & 0.35 & 0.45 & 0.56 & 0.07 & 1.69 & - & - \\
$\begin{array}{c}\text { Bay[7] } \\
\text { Fujian[7] }\end{array}$ & 0.018 & 0.45 & 0.26 & 0.10 & 1.90 & - & - \\
$\begin{array}{c}\text { Zhejiang[7] } \\
\text { Liaoning[7] }\end{array}$ & 0.026 & 0.53 & - & 0.76 & - & - & - \\
Xiangshan & 0.029 & 0.04 & - & 0.29 & 1.06 & - & - \\
$\begin{array}{c}\text { Port[8] } \\
\text { Xiangshan } \\
\text { Gang[6] }\end{array}$ & 0.044 & 0.125 & 1.048 & 0.072 & 1.432 & - & - \\
\hline
\end{tabular}

\section{CONCLUSIONS}

The main harmful substances in the Ruditapes philippinarum at the sea water of Xiangshan Bay is $\mathrm{Hg}, \mathrm{Pb}$, As, $\mathrm{Cd}, \mathrm{Cu}, \mathrm{Zn}, \mathrm{Cr}$, Petroleum hydrocarbons, polychlorinated biphenyls, Fecal coliforms. The harmful substances increase with the growing of individuals, and they are closely related to the water quality of sea areas and the bottom environmental quality. But most of the sea areas of Xiangshan Bay accord with A class sea water quality, the contents of harmful substances in Ruditapes philippinarum don't exceed the specified standard, so they can be used for the group to eat safely.

\section{ACKNOWLEDGMENT}

This work was financially supported by the National Natural Science Foundation of China (Grant No.41176142); The Zhejiang Provincial Natural Science Foundation(Y14D060031); The Basic Scientific Research Fund of SIO, China(JG1412).

\section{REFERENCES}

[1] Chen Xiukai,Tian Huijuan,Liu Jitan,Wang Weizhi,Contents and distributions of heavy metals in sea water,sediments and shellfishes in Haizhou Bay.J. Inspe.Quarnt.,2009,19(5):6-11.

[2] Cui Yi, Song Yunli and Chen Bijuan,The assessment on the contents of the heavy metals in organisms along coast of Huanghua.Marine Fisheries Res.,2000,21(2):55-60.

[3] Du Rui-xue,Fan Zhong-xue,Wei Ai-li et al,Content analysis of heavy metal in economic shellish from Shandong coast.Shandong Agric. Sci.,2009,8:58-63.

[4] He guangka, Levels of heavy metals in molluscs from the coastal region of Bohai Sea and Huanghai Sea.China Environm. Sci.,1996,16(2):96-100.

[5] Wang Jin-hui,Qin Yu-tao,Sun Ya-wei, et al., The distribution and source aquaculture sea of heavy metals in an important area Xiangshan Bay. Marine Fisheries,2005,27(3):226-231.

[6] Wang Xian-gang, ZhangWei- bi ng,Zhou ying et al,Study on heavy metals in the economic shellfish along the coast of Nantong. Marine Fisheries Res.,2003,24(3):45-49.

[7] Xu Jie, Qiao Qing-lin, Cai You-qiong, et al, Pollution Status and Depuration of Ruditapes philippinarum from Jiaozhou Bay Shandong.J. Zhejiang Ocean Univ.,2006,25(3):249-253.

[8] Zhao Ruisheng,Zhu Xiadi,Yah Jinlian,Preliminary analysis on the heavy metal contents of short-necked Clam in Xiangshan Port and Sanmen Bay.Mar.Fish.,1996,18(4):155-157.

[9] Zheng Yan,Cai Lei-ming, Investigation on pollution in Ruditapes philippinarum in the Fuzhou Shellfish culture sea areas.J. Fujian Fisher.,2009,4:62-66.

[10] Zhu Gen-hai, Wei-hua Feng, Mao Jin and Li-hong Chen,The Distribution of Microphytoplankton and Heavy Metal Content of Xiangshan Bay in Spring. Advanced Materials Research Vols. 864867 (2014) pp 428-433.

[11] Zhu Gen-hai, Mao Jin, Yi-bo Liao, Jian Zhang, Qing-song Shi, Quan-zhen Chen, Study on Impacts of Net-cage Culture on Marine Benthos in Xiangshan Bay East China Sea. Frontiers of Energy and Environmental Engineering(Sung,Kao \& Chen(eds), Taylor \& Francis Group, London,ISBN978-0-415-66159-1), (2013) pp 493497.

[12] Zhu Gen-hai,The study and analysis on seasonal variations of nano- and microalgae in stomach contents of Ruditapes philippinarum in Xiangshan Bay.Advanced Materials Research Vols.955-959(2014)pp517-522.

[13] Standard for Monitoring Committee,Standard for marine monitoring.Beijing:Ocean Press,2007,5-12.

[14] National Environmental Protect Bureau.Analytical methods for water and wastewater. Beijing:Chinese Environmental Science Press, 1989,233-251.

[15] People's Republic of China Ministry of Agriculture. GB 18406.42001 quality and safety of agricultural products Aquatic Safety Requirements [s]. Beijing: China Standard Press, 2002: 1-6.

[16] State Oceanic Administration. GB 18421--2001 quality marine organisms [s]. Beijing: China Standard Press, 2002: 1-3.

[17] Abbe G. R, Riedel G. F, Sanders J. G. Factors that influence the acumulation of copper and cadmium by transplanted eastern oysters (Crassostrea virginica) in the Patuxent River. Marland,Marine Environment Research,2000,49:377-396.

[18] Mok J.S., Kwon J.Y, Son K.T., et al,Contents and risk assessment of heavy metals in marine invertebrates from Korean coastal fish markets. J. Food Prot. 2014,77(6):1022-1030. 